第 S54 次学术讨论会 -中国长寿命路面关键科学问题及技术前沿

\title{
长寿命路面技术发展与实践
}

王旭东*，肖倩*

交通运输部公路科学研究院, 北京 100088

* 联系人, E-mail: xd.wang@ @rioh.cn; q.xiao@rioh.cn

\section{Development and practice of long-life pavement technology}

\section{Xudong Wang ${ }^{*} \&$ Qian Xiao*}

Research Institute of Highway, Ministry of Transport, Beijing 100088, China

*Corresponding authors, E-mail: xd.wang@rioh.cn; q.xiao@rioh.cn

doi: 10.1360/TB-2020-1043

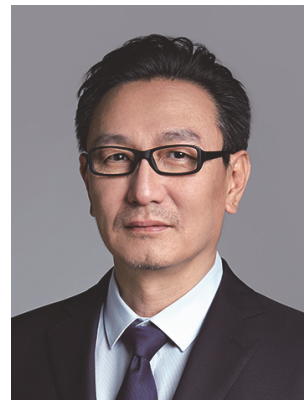

\section{主旭东}

交通运输部公路科学研究院首席研究员, 中国公路学会专家委员会委员, 国家有突 出贡献中青年专家, 交通部首批“新世纪 十百千人才工程”第一层次人选, 荣获第 十届“中国青年科技奖”, 入选国家百千万 人才工程. 足尺路面试验环道 (RIOHTrack) 试验研发团队负责人, 中国 长寿命励青路面技术研发的实践者. 主要 从事长寿命路面建养技术研究.
路面工程是交通基础设施的重要组成部分. 改革开放 40 多年, 我国建成了以高速公路为骨架的国家干线公路网, 高速公路通车 总里程居世界第一, 我国的路面工程技术也随之从学习吸收到集 成创新, 实现了跨越式发展.

当前, 国家颁布了《交通强国建设纲要》，提出了强化前沿关 键科技研发、完善科技创新机制、提升交通基础设施本质安全水平 的战略要求. 路面工程作为体量最大的基础设施, 需要从追求速度 规模向更加注重质量效益转变. 研发符合国情的长寿命路面建养 技术将是未来推动我国路面工程提质增效转型发展的重要方向.

路面工程是由多种材料组成的形式多样的层状复合结构, 在 长期服役期间表现出多元化、非线性的服役行为特征. 百多年来, 现代路面技术发展的经验表明, 长期性能的科学观测、多尺度材料 与结构的行为特征研究、复杂力学状态的行为机理分析以及工艺技 术与工程装备的革新是实现路面技术进步的主要途径.

与传统路面技术相比, 长寿命路面的服役周期将延长 2 3 倍. 长寿命路面技术的研发不仅仅是路面使用寿命在量上的大幅增加, 更是对路面材料与结构在全寿命服役周期内性能演化规律更深层 次的认知, 是对路面设计理论与指标的合理性、方法与模型的可靠 性“质”的提升, 是路面工程建造体系本质性的跨越.

为此, 以路面工程为主、多学科跨领域的专家学者齐聚北京, 于 2019 年 10 月召开了以“中国长寿命路面关键科学问题及技术前 沿”为主题的香山科学会议. 与会学者围绕以下 4 个中心议题: (1) 路面足尺试验的目标与科学问题; (2) 路面工程感知与科学数据交 汇; (3) 长寿命路面服役性能的智能仿真理论与模型; (4) 路面工程 中的复杂力学问题与新体系等, 针对我国路面工程的现状, 提出了 


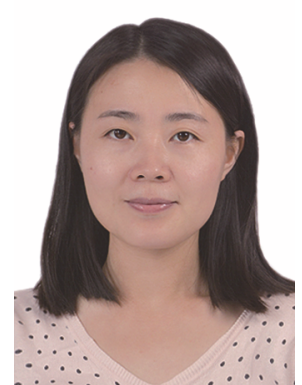

尚倩

交通运输部公路科学研究院副研究员. 获 得中国公路学会科技进步二等奖 1 项, 中 国产学研合作促进会成果创新一等奖 1 项. 主要从事与励青路面长期性能研究相关 的沥青路面材料与结构研究以及相关技 术的应用研究工作.
长寿命路面技术发展的两阶段目标：到 2035 年, 我国高速公路沥 青路面使用寿命由现在的 15 年延长至 30 年; 到 21 世纪中叶, 再延 长至 50 年, 达到世界领先水平.

长寿命路面在设计理论、建造技术、工艺装备等方面与传统科 学理论和实践体系存在本质差异, 是传统体系的重大革新, 仍需要 大量基础性科研工作的支撑. 为了帮助读者们进一步了解长寿命 路面技术领域的前沿发展, 本专辑汇集了与会专家代表性的学术 论文, 分别从长寿命路面设计体系 ${ }^{[1 ~ 3]}$ 、材料 ${ }^{[4 \sim 6]}$ 、结构 ${ }^{[7,8]}$ 、使用功 能 ${ }^{[9]}$ 及足尺模拟验证 ${ }^{[10,11]}$ 等方面展示了作者对长寿命路面技术的思 考与科研实践. 希望本专辑文章能给读者一些启发, 为推动我国长 寿命路面技术的发展作一点贡献.

\section{参考文献}

1 Zheng J L, Lü S T, Liu C C. Technical system, key scientific problems and technical frontier of long-life pavement (in Chinese). Chin Sci Bull, 2020，65：3219-3227 [郑健龙，吕松涛，刘超超. 长寿命路面的技术体系及关键科学问题与技术前沿. 科学通报，2020，65: 3219-3227]

2 Feng D C, Wang D S, Yi J Y, et al. Designation principle and method for functionally graded composite pavement (in Chinese). Chin Sci Bull, 2020, 65: 3270-3286 [冯德成, 王东升, 易军艳, 等. 梯度功能复合路面设计原理与实现方法. 科学通报, 2020, 65: 3270-3286]

3 Wang L, Wei J C, Zhang X M, et al. "Four integrations" to solve the technical bottleneck of long-life asphalt pavement (in Chinese). Chin Sci Bull，2020，65：3238-3246 [王林，韦金城，张晓萌，等。“四个一体化”破解长寿命沥青路面技术瓶颈。科学通报，2020，65: 3238-3246]

4 Tang B M, Ding Y J, Su Y, et al. Viscosity estimation of model asphalt based on free volume theory (in Chinese). Chin Sci Bull, 2020, 65: 3308-3317 [唐伯明，丁勇杰，苏玥，等. 基于自由体积理论的沥青分子模型黏度预测. 科学通报, 2020, 65: 3308-3317]

5 Chen Z, Liang Y L, Guo Z Y, et al. A novel technique for asphalt pavement interlayer contact condition diagnosis (in Chinese). Chin Sci Bull, 2020, 65: 3318-3327 [陈长, 梁远路, 郭忠印, 等. 沥青路面结构层间接触状况诊断新方法. 科学通报, 2020, 65: 3318-3327]

6 Sha A M, Jiang W, Wang W T, et al. Design and prospect of new pavement materials for smart road (in Chinese). Chin Sci Bull, 2020, 65: 3259-3269 [沙爱民，蒋玮，王文通，等. 面向智慧道路建造的新型路面材料设计与展望. 科学通报, 2020, 65: 3259-3269]

$7 \mathrm{Hu}$ Y, Zang G S, Sun L J, et al. Determination of optimal identity points for backcalculating the structural layer moduli of asphalt pavement (in Chinese). Chin Sci Bull, 2020, 65: 3287-3297 [胡玥, 藏国帅, 孙立军, 等. 沥青路面结构层模量反演最佳特征点的确定. 科 学通报, 2020, 65: 3287-3297]

8 Wang X D, Zhou X Y, Guan W, et al. Characteristics and analysis of the mechanical response inside the structure of asphalt pavement (in Chinese). Chin Sci Bull, 2020, 65: 3298-3307 [王旭东, 周兴业, 关伟, 等. 沥青路面结构内部的力学响应特征及分析. 科学通报, 2020, 65: 3298-3307]

9 Huang X M, Jiang Y M, Zheng B S, et al. Theory and methodology on safety braking of autonomous vehicles based on the friction characteristic of road surface (in Chinese). Chin Sci Bull, 2020, 65: 3328-3340 [黄晓明, 蒋永茂, 郑彬双, 等. 基于路表摩擦特性的无人 驾驶车辆安全制动原理与方法. 科学通报, 2020, 65: 3328-3340]

10 Zhang L, Zhou X Y, Wang X D. Research progress of long-life asphalt pavement behavior based on the RIOHTrack full-scale accelerated loading test (in Chinese). Chin Sci Bull, 2020, 65: 3247-3258 [张蕾, 周兴业, 王旭东. 沥基于 RIOHTrack 足尺加速加载试验的长寿命 沥青路面行为研究进展. 科学通报, 2020, 65: 3247-3258]

11 Wang S J, Ma T, Zhang W G, et al. Experience and challenges of long-term performance research on asphalt pavement (in Chinese). Chin Sci Bull, 2020, 65: 3228-3237 [汪双杰, 马涛, 张伟光, 等. 沥青路面长期性能研究的经验与挑战. 科学通报, 2020, 65: 3228-3237] 